\title{
Different disc characteristics between young elite skiers with diverse training histories revealed with a novel quantitative magnetic resonance imaging method
}

\author{
K. Lagerstrand ${ }^{1,2} \cdot$ A. Baranto ${ }^{1,3} \cdot$ H. Hebelka $a^{1,4}$
}

Received: 9 October 2020 / Revised: 5 March 2021 / Accepted: 2 May 2021 / Published online: 19 May 2021

(c) The Author(s) 2021

\begin{abstract}
Purpose To evaluate if there are differences in thoraco-lumbar disc characteristics between elite skiers and non-athletic controls as well as between different types of elite skiers, with diverse training histories, using a novel quantitative MRI method. Methods The thoraco-lumbar spine of 58 elite skiers (age $=18.2 \pm 1.1$ years, 30 males) and 26 normally active controls (age $=16.4 \pm 0.6$ years, 9 males) was examined using T2w-MRI. Disc characteristics were compared quantitatively between groups using histogram and regional image analyses to determine delta peak and T2-values in five sub-regions.

Results A statistical difference in the delta peak value was found between skiers and controls $(p<0.001)$, reflecting higher degree of disc degeneration. The histogram analysis also revealed that the type of training determines where and to what extent the changes occur. Alpine skiers displayed lumbar changes, while mogul skiers displayed changes also in the thoracic spine. Alpine skiers with diverse training dose differed in delta peak value $(p=0.005)$, where skiers with highest training dose displayed less changes. Regional T2-value differences were found in skiers with divergent training histories $(p<0.05)$, reflecting differences in disc degeneration patterns, foremost within the dorsal annulus.

Conclusion Differences in quantitative disc characteristics were found not only between elite skiers and non-athletic controls but also between subgroups of elite skiers with diverse training histories. The differences in the disc measures, reflecting tissue degradation, are likely related to type and intensity of the physical training. Future studies are encouraged to explore the relation between disc functionality, training history and pain to establish adequate prevention and rehabilitation programs.
\end{abstract}

Keywords Magnetic resonance imaging $\cdot$ Disc $\cdot$ Athletes $\cdot$ Sport $\cdot$ Injury prevention program

\section{Introduction}

Skiing is a high-risk sport with high loads affecting the body [1-3]. Not only spinal traumas but also the repetitive loading of the spine might damage the spinal tissues [4]. In similar with other groups of athletes [5-8], the incidence of spinal

K. Lagerstrand

kerstin.lagerstrand@vgregion.se

1 Institute of Clinical Sciences, Sahlgrenska Academy, University of Gothenburg, Gothenburg, Sweden

2 Department of Medical Physics and Techniques, Sahlgrenska University Hospital, Gothenburg, Sweden

3 Department of Orthopedics, Sahlgrenska University Hospital, Gothenburg, Sweden

4 Department of Radiology, Sahlgrenska University Hospital, Gothenburg, Sweden abnormalities in skiers has been reported to be significant already at a young age $[9,10]$. This might be an effect of the increased level of competition, as well as higher doses of training without long rest in-between, for longer periods of time, starting at a young age [11-14]. Also, the specialization in one singular sport, at a young age, with concomitant limitation in training variability may also increase the risk of overuse injuries.

In athletes with great demands on their spine, spinal abnormalities, such as advanced disc degeneration, apophyseal ring injury, sacral stress fracture, disc herniation, spondylolysis and ligament tears are highly represented [5-8]. Also, back pain is a common complaint in athletes with an incidence up to $90 \%$ in some studies [15-18], especially after training progression [15].

However, an association between back pain and radiological findings has not been fully established for all sports. This may be due to the fact that most studies are based on plain 
radiographs or on conventional MRI $[9,10,19,20]$. Such methods lack objective markers that can detect changes in detail on a continuous scale of measurement and, thereby, enable characterization of early changes in these subjects.

New methods, which rely on MRI as well as on advanced image analysis, have recently been proposed for quantitative assessment of disc characteristics [21, 22]. The methods have been shown to detect not only global but also detailed dysfunctional disc behaviours associated with annular fissuring and remodelling of the nucleus pulposus in chronic low back pain patients. The methods may also have the feasibility to detect subtle disc changes in athletes related to physical training histories. With trainings-related spinal markers, evidence-based facts can be established and from such knowledge, injury prevention programs (IPPs) and rehabilitation programs can be developed for prevention of future spinal injuries.

The aim of the study was to evaluate if there are differences in thoraco-lumbar disc characteristics between young elite skiers with diverse physical training histories and between young skiers and a non-athletic control group using novel quantitative MRI analysis.

\section{Materials and methods}

\section{Subjects}

The present study includes a secondary analysis of an existing MRI dataset, collected to identify differences in degenerated disc changes between young elite skiers $(n=58$, age $=18.2 \pm 1.1$ years, 30 males) and normally active controls $(n=26$, age $=16.4 \pm 0.6$ years, 9 males $)$ using gross morphological evaluation of spinal changes and a conventional categorical classification system for disc degeneration, i.e. Pfirrmann grading [23].

The inclusion criterion for skiers was: training and competing at an elite level at Åre Ski Academy, Östersund, Sweden. For the control group, normally active first-year high school students were recruited from Jarpen and Östersund, Sweden with inclusion criteria: no previous nor present participation in any organized sport activities or training more the $2 \mathrm{~h}$ per week. Exclusion criteria for both groups were: episode of serious traumatic injury of the thoraco-lumbar spine or a history of previous surgery on the spine, pelvis or hip joints as well as pregnancy and any history of systemic disease including inflammatory arthritis or pelvic inflammatory disorders.

The study was approved by the Regional Ethical Review Board in Gothenburg at Sahlgrenska Academy, University of Gothenburg, Gothenburg, Sweden (ID NR: 2013-69213 and 2020-01657). Both the participants and their parents received written and oral information about the study.
In this study, evaluating disc characteristic with a novel quantitative MRI method, the group of skiers were further subcategorized into three groups with diverse physical training histories: mogul skiers, and NIU (Nationell IdrottsUtbildning $=$ nationally approved sport education) and RIG (RiksIdrottsGymnasium $=$ Swedish national sport gymnasium with highest national sport level) alpine skiers. The RIG skiers had at admission to the Ski Academy the highest ranking in Sweden or were assumed to have the best development potential in comparison with the NIU skiers. The training dose was investigated through questionaires including present and previous athletic performance and activity level, where the current activity level was further categorized according to the number of training hours per week.

\section{MRI examination}

All subjects were examined with MRI at the Department of Radiology at Östersund Hospital, Sweden, using a 1.5 T (HDXt Signa Echospeed, General Electrics, Madison, USA). The thoraco-lumbar spine, covering T5 to S3, was examined using standardized MRI sequences, including a T1-weighted sequence $(\mathrm{FOV}=480 \mathrm{~mm}$, slice thickness $=4$ $\mathrm{mm}, \mathrm{TR}=560 \mathrm{~ms}, \mathrm{TE}<90 \mathrm{~ms})$ and a T2-weighted (T2w) sequence in the sagittal view (FOV $=480 \mathrm{~mm}$, slice thickness $=4 \mathrm{~mm}$, TR $=4463 \mathrm{~ms}$, $\mathrm{TE}=110 \mathrm{~ms}$ ).

\section{Conventional MRI}

Morphological evaluation of degenerative disc changes, using categorical classifications systems, has previously been reported and any further evaluation of morphological changes were not part of the current study [20].

\section{Quantitative MRI}

To characterize disc degradation quantitatively, histogram and regional T2 image analysis were performed. These quantitative analysis methods are summarized below and described in detail by Waldenberg et al. [21]. In short, each disc was semi-automatically outlined on three (lumbar discs), respectively, two (in the smaller thoracic discs) consecutive mid-sagittal T2w images using a segmentation software based on MATLAB (R2016b, Mathworks, Natick, Massachusetts, U.S.A.). The segmentation was performed by a senior radiologist specialized on spine diagnostics (H.H.). The intra- and inter-observer reliability for the disc segmentation using the software tool have previously been determined on a similar cohort with a high degree of consensus (ranging between 0.79 and 0.99 depending on sub-region) [24]. From the segmented discs, signal histograms were plotted, where the difference between the histogram peaks, representing the nucleus pulposus and annulus fibrosus, was 
automatically extracted. Each disc was further divided into five equally large parts in the ventral-dorsal direction: (1: ventral annulus fibrosus, 2: border zone between annulus fibrosus and ventral part of nucleus pulposus, 3 : central part of nucleus pulposus, 4: border zone between dorsal part of nucleus pulposus and dorsal annulus fibrosus and 5: dorsal annulus fibrosus). From these volumetric sub-regions, the mean T2-value was extracted and normalized to the mean value over the entire disc. The quantitative MRI markers, i.e. the delta peak value as well as the five sub-regional values, were compared between skiers and controls, as well as between subgroups of skiers with diverse physical training histories (Fig. 1).

\section{Statistical analysis}

The statistical analysis was performed using the Anaconda platform with the Python distribution (Anaconda Software Distribution. Computer software. Vers. 2-2.4.0. Anaconda, Nov. 2016).

Violin plots, displaying the probability density of data, were used to visualize differences in the delta peak value between controls, skiers, alpine skiers, NIU skiers, RIG skiers, and mogul skiers for the whole thoraco-lumbar spine as well as for the thoracic and lumbar spine separately.

The mean T2-value at different sub-regions of the discs and the standard deviation of the mean were plotted, visualizing differences in regional disc behaviours between skiers and controls for the whole thoraco-lumbar spine and between alpine and mogul skiers and NIU and RIG skiers for the thoracic and lumbar spine separately.

The paired $t$-test with $p \leq 0.05$, corrected for multiple testing using the Bonferroni correction, was used to statistically evaluate differences in the quantitative the quantitative MRI markers, i.e. the delta peak value and the T2-values at five different sub-regions. All statistical tests were stratified for age, sex and BMI. In specific, differences between skiers and non-athletic controls were evaluated for the whole thoracolumbar spine and differences between the mogul and alpine skiers and the NIU and RIG skiers were evaluated for the thoracic and for the lumbar spine separately.

All values are presented as mean \pm standard deviation if not otherwise stated.

\section{Results}

Table 1 presents the demographics of the subjects, separated into groups of normally active controls and skiers, as well into subgroups of different type of skiers. As can be seen in the Table, the NIU, RIG and mogul skiers differed in training dose and no subject in the control group trained more than $8 \mathrm{~h} /$ week.

Differences in disc characteristics were found not only between skiers and controls, but also between subgroups of skiers with diverse physical training histories. As shown by the violin plots in Fig. 2, the control group displayed a narrow Gaussian distribution of higher delta peak values while the skiers displayed a wider and slightly skewed distribution towards lower values, reflecting a higher degree of disc degeneration in those subjects. Also, skiers with diverse physical training history displayed different distribution patterns.

For the discs in the whole thoraco-lumbar spine, there was a statistical difference in the delta peak value between skiers and controls $(p<0.001)$. When stratified on the thoracic spine, the peak value was lower in the mogul skiers than in the alpine skiers $(p=0.019)$ but no statistical difference between NIU and RIG skiers was found $(p>0.05)$. In the lumbar spine, the peak value was significantly lower
Fig. 1 Flowchart of discs eligible for inclusion in the study. The figure displays drop-outs as well as the final numbers of discs for non-athletic controls and subgroups of skiers
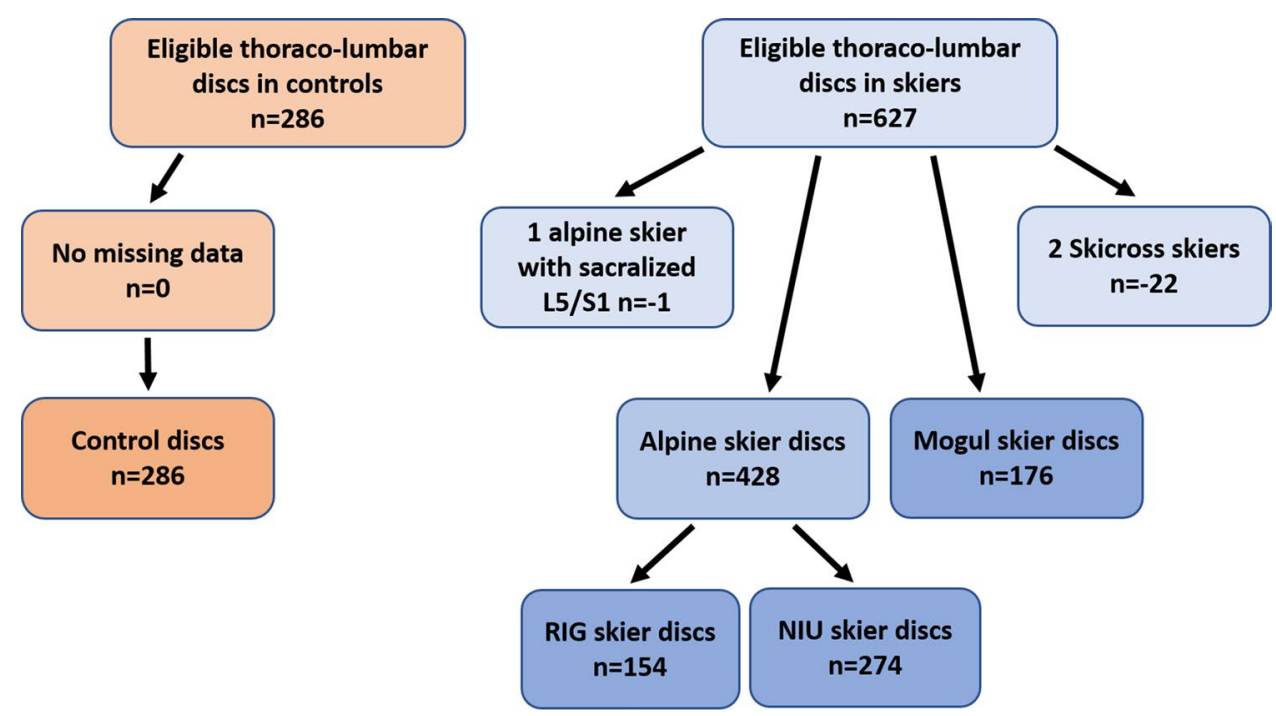
Table 1 Demographics for different cohorts

\begin{tabular}{|c|c|c|c|c|c|c|c|c|c|}
\hline \multirow[t]{2}{*}{ Group } & \multirow[t]{2}{*}{$\begin{array}{l}\text { Number of } \\
\text { subjects }\end{array}$} & \multirow[t]{2}{*}{ Number of men } & \multirow[t]{2}{*}{ Age (years) } & \multirow[t]{2}{*}{ BMI } & \multicolumn{5}{|c|}{$\begin{array}{l}\text { Percentage number of subjects } \\
\text { with training dose (h/week) }\end{array}$} \\
\hline & & & & & $<2$ & $3-5$ & $6-8$ & $9-11$ & $>11$ \\
\hline Controls & 26 & 9 & $16.4 \pm 0.6$ & $22.9 \pm 5.3$ & 32 & 44 & 24 & - & - \\
\hline Skiers & 58 & 30 & $18.2 \pm 1.1$ & $23.1 \pm 2.2$ & - & 2 & 22 & 38 & 38 \\
\hline Alpine skiers & 38 & 16 & $18.1 \pm 1.1$ & $23.3 \pm 2.0$ & - & 3 & 26 & 47 & 24 \\
\hline NIU skiesr & 24 & 7 & $18.0 \pm 1.2$ & $23.1 \pm 2.1$ & - & 5 & 29 & 58 & 8 \\
\hline RIG skiers & 14 & 9 & $18.1 \pm 1.1$ & $23.6 \pm 1.7$ & - & - & 21 & 29 & 50 \\
\hline Mogul skiers & 17 & 15 & $18.5 \pm 1.1$ & $22.5 \pm 2.7$ & - & - & 12 & 18 & 70 \\
\hline
\end{tabular}

$B M I$ Body mass index

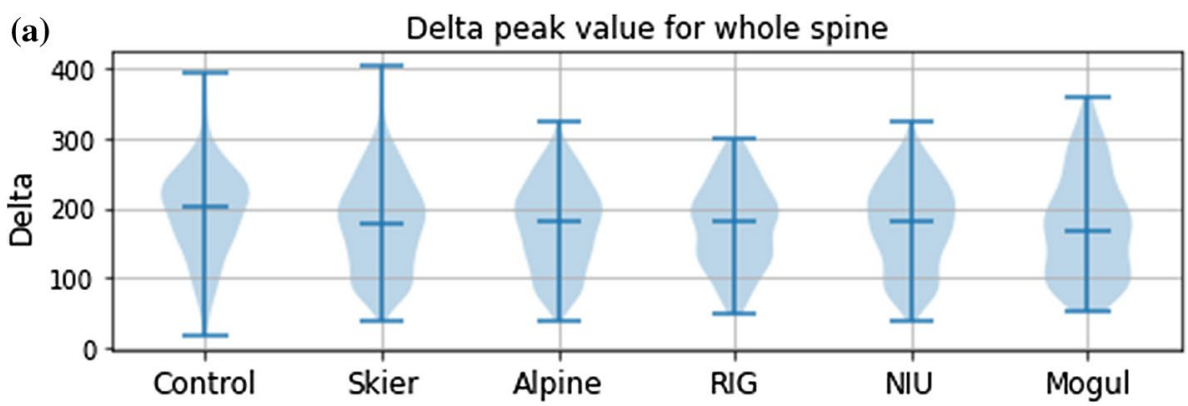

(b) Delta peak value for thoracal spine



(c) Delta peak value for lumbar spine

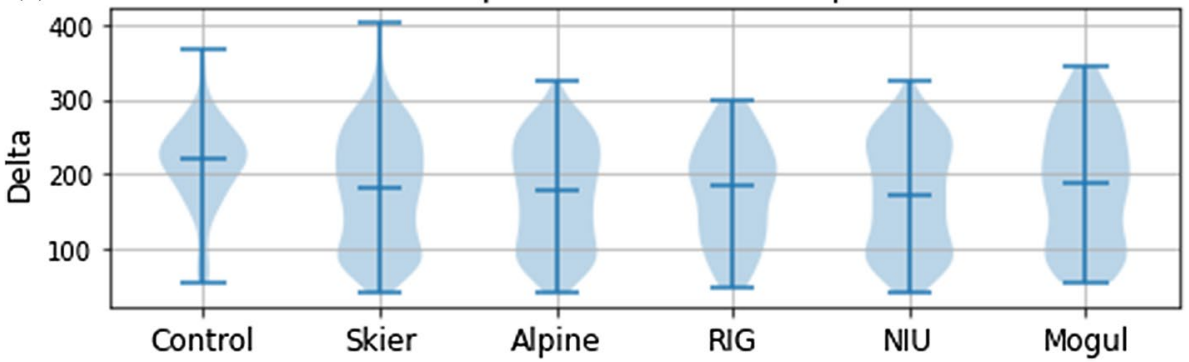

for the NIU skiers than for the RIG skiers $(p=0.005)$ with a larger spread of values. However, no statistical differences between mogul skiers and alpine skiers was found in the lumbar spine.

The regional T2-distribution plots (Fig. 3) showed that the differences in disc characteristics between groups, detected with the delta peak value, displayed a regional dependence.
A statistically significant difference in the regional T2-distribution was found between skiers and controls for the discs in the whole thoraco-lumbar spine at sub-region $5(p=0.009)$. A significant difference between mogul and alpine skiers was found for the discs in the thoracic spine at the more posterior part of the disc, at sub-region 3: $p=0.004,4: p=0.002$ and 5: $p=0.001$. Also, a significant difference was found 
Fig. 3 Regional distribution of T2-values for different subregions of the discs ranging from 1 (anterior) to 5 (posterior). Comparisons a between skier's and control's discs in the whole thoraco-lumbar spine, b between mogul skier's and alpine skier's disc in the thoracic spine and $\mathbf{c}$ between NIU skier's and RIG skier's discs in the lumbar spine, represented as two overlapping patches of different colours. The height of each patch visualizes the $\mathrm{T} 2$ mean \pm 1 standard deviation of the mean
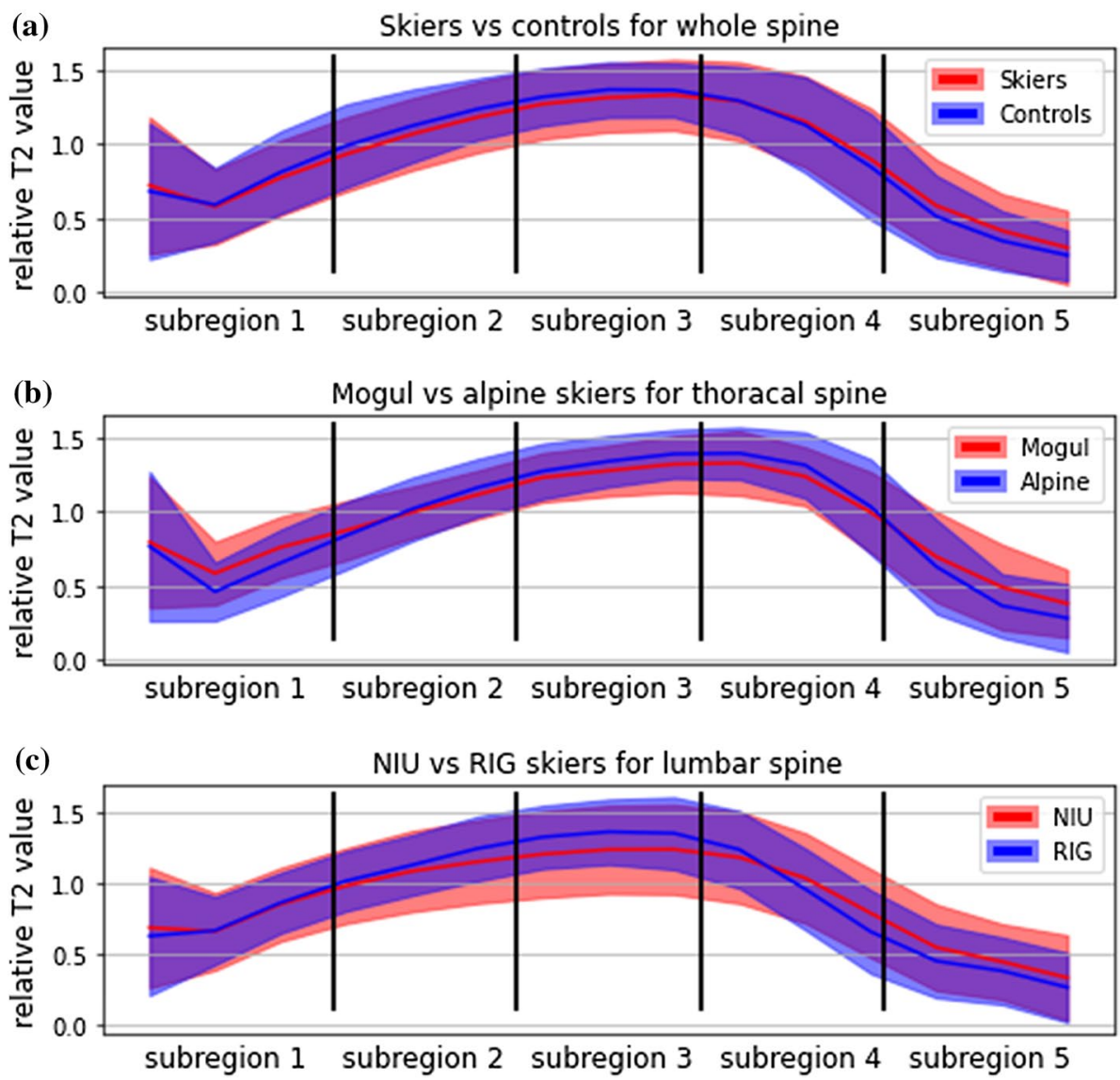

between NIU and RIG skiers for the discs in the lumbar spine at sub-region $5(p=0.05)$.

\section{Discussion}

The present study not only supports the hypothesis that high dose athlete training degrades body tissues [5-8], but also shows that the type of training determines where and to what extent the changes occur. The young elite skiers and normally active controls were found to differ in disc characteristics, probably related to disc degeneration secondary to overload of the spine with excessive lengthy training starting from young age [12, 22]. Our findings also revealed different disc behaviours between subgroups of skiers, suggesting that the impact of overloading on the spine might be different between these groups. The alpine skiers had more disc changes in the lumbar spine, while the mogul skiers displayed changes in both the lumbar and thoracic spine. Most probably, this can be traced back to the differences in body position during the impact of loading, where the transient loads during hump piste skiing seem to damage the smaller and more sensitive thoracic discs. Also, alpine skiers with diverse training dose differed in findings. Interestingly, the alpine skiers with highest training dose, i.e. RIG, displayed a smaller variation in disc behaviours with less disc changes in the lumbar spine. This may be due to differences in sagittal spinal curves. Athletes with low Pelvic Incidence (Roussouly type 1 and 2) have shown to have more disc degeneration and disc hernia due to heavy loads affecting the anterior part of the spine [25]. The sagittal spinal curves may therefore be a factor to consider among athletes with different loads on the spinal. Effective IPP and rehabilitation program for prevention of spinal injuries might also have contributed to this difference. The IPPs do not only include active skiing, but also general fitness exercises for improved strength and stabilization of the important muscle groups. The higher training dose might have been supportive for the tissues at risk and consequently prevented future spinal injuries in the RIG skiers.

Subgroups of skiers did not only differ in the global heterogeneity marker (delta peak value) but displayed characteristically different regional disc behaviours. The distribution of T2-values over thoraco-lumbar discs was slightly different in skiers in comparisons with controls and the thoracic discs of the mogul and the lumbar discs of the NIU skiers displayed different distributions in comparison with the alpine and RIG skiers, respectively. Previous studies have assigned this regional behaviour to annular fissuring. Disc fissures that extends deep into the annulus fibrosus can contain antigenic 
nucleus pulposus material trapped between torn lamellae structures in annulus fibrosus that induce inflammation and ingrowth of vascularized granulation tissue deep into the discs [26, 27]. These so-called HIZ fissures have been found to be associated with significantly higher T2-values at the posterior annular region of the discs [28] and significantly lower T2-values at the nucleus pulposus region, probably reflecting reduced hydration [21, 26, 28-30]. The T2 distribution plots in Fig. 3 displayed such behaviour, but the difference in $\mathrm{T} 2$-value at the position of the nucleus pulposus could not be statistically verified. The presence of HIZ, which likely explains the regional behaviour, may promote discogenic pain in those individuals [26, 31]. To establish evidence-based facts and improve the understanding of training-related disc changes and their relation to long-time prevalence of back pain in skiers, we plan to perform a longitudinal follow-up study of the included subjects.

As the growing tissue is more sensitive, young athletes run a higher risk of developing spinal injuries. Present findings suggest that participation in alpine skiing at an early age increases the risk to develop training-related spinal abnormalities over time. Sports have many benefits, especially when the activity is compared with the sedentary lifestyles of too many children all over the world. However, elite training is progressively becoming more prevalent at an earlier age and the higher risks of musculoskeletal disorders and the psychologic stress of repetitive and monotonous sports activities for several hours a day are concerning [11-14]. To control the extreme overuse encouraged and supervised by the society, ethical rules and committees that regulate the training and competing seem to be needed for these children.

Our findings, which are in concordance with previous studies investigating spinal abnormalities in other athlete sports [4, 23, 29, 33], highlights the awareness of overuse injuries and the importance of developing effective IPPs. To provide effective injury prevention as well as performanceenhancing benefits, it is recommended that the IPP should be designed to consider typical injury profiles for the sport of interest [32]. Our findings revealed different disc behaviours between subgroups of skiers, suggesting that separate IPPs should be designed for the mogul and alpine skiers to suit their specific needs. As their performance of sports places completely different demands on their spinal tissues, the IPPs should be more specific and include preparation exercises for improved strength of the lumbar muscles in alpine skiers and thoraco-lumbar muscles in mogul skiers.

The detection of tissue changes is limited using the conventional diagnostic methods that are available today. Standardized MRI protocols, including T1-weighted and T2-weighed sequences have intrinsically high sensitivity to detect degenerative tissue changes in the spine, but the categorization schemes that are used for the image evaluation are known to be unsensitive and unspecific [33]. As such, changes in tissue structure can remain undetected even though they are present in the images. The proposed MRI method was able to detect training-related disc changes, not previously shown by the conventional interpretation methods performed in clinical routine [20]. Moreover, the method characterizes disc degradation as quantitative values. Quantitative markers are suitable to monitor spinal changes longitudinally over time and could have wide applications in the search for novel preventative strategies in young athletes. Also, the proposed method may offer quantitative biomarkers that can provide, at an earlier stage, the opportunity to detect dysfunctional behaviours and offer a non-invasive, non-ionizing diagnostic tool that can characterize sportrelated injury profiles used in the development of IPPs.

\section{Limitations}

A potential limitation of this study could be selection bias. Only subjects with moderate spinal abnormalities are represented in the groups of skiers, as subjects with severe back pain and/or spinal abnormalities most probably need to cease the sport. Also, since spinal sagittal alignment was not evaluated as part of this study, it cannot be excluded that such selection bias could have influenced the results. Future studies should focus on the correlation between sagittal spinal curves and different spinal pathologies between subgroups but also within the same subgroups at different field positions, ages, technics, etc. Nonetheless, the present study displays that sophisticated quantitative disc measures are valuable for evaluation of disc affection in detail.

\section{Conclusion}

Differences in quantitative disc characteristics were found not only between elite skiers and normally active controls but also between subgroups of elite skiers with diverse training histories. The differences in quantitative disc measures, reflecting tissue degradation, likely relates to the type and intensity of the physical training. Future studies are encouraged to explore the relation between disc functionality, training history and pain to establish adequate prevention and rehabilitation programs.

Acknowledgements The authors would like to thank Christian Waldenberg at the Department of Medical Physics and Techniques, Sahlgrenska University Hospital, Gothenburg, Sweden, for his help with the advanced image analysis.

Funding Open access funding provided by University of Gothenburg. The study was financed by grants from the Swedish state under the 
agreement between the Swedish government and the country councils, the ALF-agreement.

Data availability All images are available on request.

Code availability The off-line post-processing software code is available on request.

\section{Declarations}

Conflicts of interest None of the authors has any potential conflict of interest.

Ethics approval The study was conducted according to the Declaration of Helsinki. Ethical approval was given by The Regional Ethics Review Board (ID NR 2020-01657)

Human and animal rights All procedures performed in studies involving human participants were in accordance with the ethical standards of the institutional and/or national research committee and with the 1964 Helsinki Declaration and its later amendments or comparable ethical standards.

Informed consent Informed consent was obtained from all individual participants included in the study. Oral and written informed consent was obtained from all participants before entering any part of the study. Oral and written informed consent was obtained from all participants.

Open Access This article is licensed under a Creative Commons Attribution 4.0 International License, which permits use, sharing, adaptation, distribution and reproduction in any medium or format, as long as you give appropriate credit to the original author(s) and the source, provide a link to the Creative Commons licence, and indicate if changes were made. The images or other third party material in this article are included in the article's Creative Commons licence, unless indicated otherwise in a credit line to the material. If material is not included in the article's Creative Commons licence and your intended use is not permitted by statutory regulation or exceeds the permitted use, you will need to obtain permission directly from the copyright holder. To view a copy of this licence, visit http://creativecommons.org/licenses/by/4.0/.

\section{References}

1. Ackery A, Hagel BE, Provvidenza C, Tator CH (2007) An international review of head and spinal cord injuries in alpine skiing and snowboarding. Inj Prev 13:368-375. https://doi.org/10.1136/ ip.2007.017285

2. Florenes TW, Heir S, Nordsletten L, Bahr R (2010) Injuries among world cup freestyle skiers. Br J Sports Med 44:803-808. https://doi.org/10.1136/bjsm.2009.071159

3. Meyers MC, Laurent CM Jr, Higgins RW, Skelly WA (2007) Downhill ski injuries in children and adolescents. Sports Med 37:485-499. https://doi.org/10.2165/00007256-200737060-00003

4. Sporri J, Kroll J, Haid C, Fasel B, Muller E (2015) Potential mechanisms leading to overuse injuries of the back in alpine ski racing: a descriptive biomechanical study. Am J Sports Med 43:2042-2048. https://doi.org/10.1177/0363546515588178

5. Baranto A, Hellstrom M, Nyman R, Lundin O, Sward L (2006) Back pain and degenerative abnormalities in the spine of young elite divers: a 5-year follow-up magnetic resonance imaging study.
Knee Surg Sports Traumatol Arthrosc 14:907-914. https://doi. org/10.1007/s00167-005-0032-3

6. Baranto A, Hellstrom M, Cederlund CG, Nyman R, Sward L (2009) Back pain and MRI changes in the thoraco-lumbar spine of top athletes in four different sports: a 15-year follow-up study. Knee Surg Sports Traumatol Arthrosc 17:1125-1134. https://doi. org/10.1007/s00167-009-0767-3

7. Rosendahl K, Strouse PJ (2016) Sports injury of the pediatric musculoskeletal system. Peadiatr Radiol 121:431-441. https://doi. org/10.1007/s11547-015-0615-0

8. Sjolie AN (2004) Persistence and change in nonspecific low back pain among adolescents: a 3-year prospective study. Spine 29:2452-2457. https://doi.org/10.1097/01.brs.0000143666.58758. $8 \mathrm{~b}$

9. Ogon M, Riedl-Huter C, Sterzinger W, Krismer M, Spratt KF, Wimmer C (2001) Radiologic abnormalities and low back pain in elite skiers. Clin Orthop Relat Res. https://doi.org/10.1097/00003 086-200109000-00018

10. Rachbauer F, Sterzinger W, Eibl G (2001) Radiographic abnormalities in the thoracolumbar spine of young elite skiers. Am J Sports Med 29:446-449. https://doi.org/10.1177/0363546501 0290041101

11. Adirim TA, Cheng TL (2003) Overview of injuries in the young athlete. Sports Med 33:75-81. https://doi.org/10.2165/00007256200333010-00006

12. Hogan KA, Gross RH (2003) Overuse injuries in pediatric athletes. Orthop Clin North Am 34:405-415. https://doi.org/10.1016/ s0030-5898(03)00006-3

13. Emery C, Tyreman H (2009) Sport participation, sport injury, risk factors and sport safety practices in calgary and area junior high schools. Paediatr Child Health 14:439-444. https://doi.org/ 10.1093/pch/14.7.439

14. Hootman JM, Dick R, Agel J (2007) Epidemiology of collegiate injuries for 15 sports: summary and recommendations for injury prevention initiatives. J Athl Train 42:311-319

15. Bergstrom KA, Brandseth K, Fretheim S, Tvilde K, Ekeland A (2004) Back injuries and pain in adolescents attending a ski high school. Knee Surg Sports Traumatol Arthrosc 12:80-85. https:// doi.org/10.1007/s00167-003-0389-0

16. Bono CM (2004) Low-back pain in athletes. J Bone Joint Surg Am 86:382-396. https://doi.org/10.2106/00004623-200402000-00027

17. Mortazavi J, Zebardast J, Mirzashahi B (2015) Low back pain in athletes. Asian J Sports Med 6:e24718. https://doi.org/10.5812/ asjsm.6(2)2015.24718

18. Peacock N, Walker JA, Fogg R, Dudley K (2005) Prevalence of low back pain in alpine ski instructors. J Orthop Sports Phys Ther 35:106-110. https://doi.org/10.2519/jospt.2005.35.2.106

19. Sadineni RT, Pasumarthy A, Bellapa NC, Velicheti S (2015) Imaging patterns in MRI in recent bone injuries following negative or inconclusive plain radiographs. J Clin Diagn Res 9:TC1013. https://doi.org/10.7860/JCDR/2015/15451.6685

20. Witwit WA, Kovac P, Sward A, Agnvall C, Todd C, Thoreson O, Hebelka H, Baranto A (2018) Disc degeneration on MRI is more prevalent in young elite skiers compared to controls. Knee Surg Sports Traumatol Arthrosc 26:325-332. https://doi.org/10.1007/ s00167-017-4545-3

21. Waldenberg C, Hebelka H, Brisby H, Lagerstrand KM (2019) Differences in IVD characteristics between low back pain patients and controls associated with HIZ as revealed with quantitative MRI. PLoS ONE. https://doi.org/10.1371/journal.pone.0220952

22. Waldenberg C, Hebelka H, Brisby H, Lagerstrand KM (2018) MRI histogram analysis enables objective and continuous classification of intervertebral disc degeneration. Eur Spine J 27:10421048. https://doi.org/10.1007/s00586-017-5264-7

23. Pfirrmann CW, Metzdorf A, Zanetti M, Hodler J, Boos N (2001) Magnetic resonance classification of lumbar intervertebral disc 
degeneration. Spine 26:1873-1878. https://doi.org/10.1097/00007 632-200109010-00011

24. Toren L, Hebelka H, Kasperska I, Brisby H, Lagerstrand K (2018) With axial loading during MRI diurnal T2-value changes in lumbar discs are neglectable: a cross sectional study. BMC Musculoskelet Disord 19:25. https://doi.org/10.1186/s12891-018-1930-0

25. Roussouly P, Pinheiro-Franco JL (2011) Biomechanical analysis of the spino-pelvic organization and adaptation in pathology. Eur Spine J 20(Suppl 5):609-618. https://doi.org/10.1007/ s00586-011-1928-x

26. Peng B, Hou S, Wu W, Zhang C, Yang Y (2006) The pathogenesis and clinical significance of a high-intensity zone (HIZ) of lumbar intervertebral disc on MR imaging in the patient with discogenic low back pain. Eur Spine J 15:583-587. https://doi.org/10.1007/ s00586-005-0892-8

27. Ross JS, Modic MT, Masaryk TJ (1989) Tears of the anulus fibrosus: assessment with Gd-DTPA-enhanced MR imaging. AJNR Am J Neuroradiol 10:1251-1254

28. Trattnig S, Stelzeneder D, Goed S, Reissegger M, Mamisch TC, Paternostro-Sluga T, Weber M, Szomolanyi P, Welsch GH (2010) Lumbar intervertebral disc abnormalities: comparison of quantitative T2 mapping with conventional MR at 3.0 T. Eur Radiol 20:2715-2722. https://doi.org/10.1007/s00330-010-1843-2

29. Sharma A, Parsons M, Pilgram T (2011) Temporal interactions of degenerative changes in individual components of the lumbar intervertebral discs: a sequential magnetic resonance imaging study in patients less than 40 years of age. Spine 36:1794-1800. https://doi.org/10.1097/BRS.0b013e31821590ad
30. Panagopoulos J, Magnussen JS, Hush J, Maher CG, Crites-Battie M, Jarvik JG, Jensen TS, Hancock MJ (2017) Prospective comparison of changes in lumbar spine MRI findings over time between individuals with acute low back pain and controls: an exploratory study. AJNR Am J Neuroradiol 38:1826-1832. https://doi.org/10. 3174/ajnr.A5357

31. Jha SC, Higashino K, Sakai T, Takata Y, Abe M, Yamashita K, Morimoto M, Fukuta S, Nagamachi A, Sairyo K (2016) Clinical significance of high-intensity zone for discogenic low back pain: a review. J Med Invest 63:1-7. https://doi.org/10.2152/jmi.63.1

32. Parkkari J, Kujala UM, Kannus P (2001) Is it possible to prevent sports injuries? review of controlled clinical trials and recommendations for future work. Sports Med 31:985-995. https://doi. org/10.2165/00007256-200131140-00003

33. Belavy DL, Brisby H, Douglas B, Hebelka H, Quittner MJ, Owen PJ, Rantalainen T, Trudel G, Lagerstrand KM (2020) Characterization of intervertebral disc changes in asymptomatic individuals with distinct physical activity histories using three different quantitative MRI techniques. J Clin Med. https://doi.org/10.3390/ jcm9061841

Publisher's Note Springer Nature remains neutral with regard to jurisdictional claims in published maps and institutional affiliations. 